Research Article

\title{
Geological Core Ground Reorientation Technology Application on In Situ Stress Measurement of an Over-Kilometer-Deep Shaft
}

\author{
Chunde Ma, ${ }^{1,2}$ Xibing Li, ${ }^{1}$ Jiangzhan Chen ${ }^{(D)},{ }^{1}$ Yanan Zhou, ${ }^{1}$ and Sen Gao ${ }^{1}$ \\ ${ }^{1}$ School of Resources and Safety Engineering, Central South University, Changsha, Hunan 410083, China \\ ${ }^{2}$ Center for Advanced Study, Central South University, Changsha, Hunan 410083, China \\ Correspondence should be addressed to Jiangzhan Chen; jiangzhanchen@csu.edu.cn
}

Received 30 July 2020; Revised 26 August 2020; Accepted 30 October 2020; Published 21 November 2020

Academic Editor: Chiara Bedon

Copyright (c) 2020 Chunde Ma et al. This is an open access article distributed under the Creative Commons Attribution License, which permits unrestricted use, distribution, and reproduction in any medium, provided the original work is properly cited.

\begin{abstract}
As mining progresses to depth, engineering activities face the extreme challenge of high in situ stress. To efficiently measure the deep in situ stress before engineering excavation, an innovative deep in situ stress measurement method capable of the geological core ground reorientation technology and acoustic emission (AE) technology was proposed. With this method, nonorientation geological cores collected from the thousand-meter-deep borehole were reoriented based on the spatial spherical geometry model and borehole bending measurement principle. The distribution of deep in situ stress of an over-kilometer-deep shaft in the Xiangxi gold mine was investigated with real-time synchronized MTS 815 material testing machine and PCI-II AE instrument. The results show that the in situ stress changes from being dominated by horizontal stress to being dominated by vertical stress with depth. The horizontal maximum principal stress and vertical stress gradually increase with depth and reach a high-stress level (greater than $25 \mathrm{MPa}$ ) at a depth of $1000 \mathrm{~m}$. The direction of the maximum principal stress is near the north. Meanwhile, to analyze the accuracy of the measured in situ stress comparatively, the stress relief measurements were performed at a depth of 655-958 $\mathrm{m}$ in the mine, using the Swedish LUT rock triaxial in situ stress measurement system. The distribution of deep in situ stress obtained by the stress relief method agrees well with that by the AE method, which proves the reliability of the AE in situ stress testing method based on the geological core ground reorientation technology.
\end{abstract}

\section{Introduction}

In situ stress is the internal stress in rock mass in the crust. It is the fundamental force that causes the deformation and failure of underground excavation structures such as mines, tunnels, and chambers [1-3]. In mining engineering, the influence of in situ stress increases with the increase in burial depth of the mine year by year [4-7]. The high in situ stress in depth causes an increased risk of rockburst and seismicity and brings significant challenges to the excavation and support of engineering structures [8-11]. Therefore, it is a necessary prerequisite to conduct measurement and understand the distribution of in situ stress in the crust for the scientific design and excavation of deep engineering structures [12-15].

At present, the investigation and development of deep in situ stress measurement technology have attracted increasing attention of many scholars and engineers [16-19]. Compared with the shallow subsurface, the complex geological conditions and limited measurement space in depth make it challenging to measure in situ stress accurately. Correspondingly, there are only a few theories and methods available for deep (over one kilometer or up to a few kilometers' depth) in situ stress measurement [1, 12, 20-22]. The theories and methods that are easy to operate, cost-effective, and readily available for largescale application are almost a blank.

For the in situ stress measurement of rock mass with considerable depth, the existing mainstream methods, such as stress relief, hydraulic fracturing, and acoustic emission (AE), have been applied in the measurement engineering, but there are some limitations in the practical applications. The stress relief method is a proven quantitative in situ stress measurement technique. However, the measurement process requires 
the measurement operator and equipment to reach the deep measurement position $[1,21]$, which significantly limits the operability of this method in deep narrow space. Besides, the uncertainty in the constitutive behavior of deep rock affects the accuracy of the stress relief method. The hydraulic fracturing method is an effective method to measure deep in situ stress but is still essentially a plane stress measurement technique. To obtain the actual three-dimensional in situ stress distribution in depth, it is necessary to perform hydraulic fracturing measurement in more than three intersection boreholes [23, 24]. Although a single borehole hydraulic fracturing method has been developed in recent years [25], the operation is complex, and many environmental conditions limit the success rate and accuracy. Compared with the former two methods, the acoustic emission (AE) method can be carried out in the laboratory with more stable test conditions and lower test costs $[19,26]$. However, this method requires special oriented coring tools to drill the orientation core in the borehole before testing. The high-cost, low-efficiency, and time-consuming oriented coring processes prevent the AE method from being effectively promoted [27]. Currently, some core orientation methods have been developed, such as paleomagnetic orientation, borehole TV, and stratigraphic scanning orientation, whereas they all have some limitations in actual engineering applications $[28,29]$. Therefore, oriented coring or core orientation in the large-depth rock mass is still a very laborious task.

In this paper, a new method for the ground reorientation of the geological core is proposed. The geological core ground reorientation technology replaces the cumbersome operation of core orientation in the large-depth borehole, making the AE method an ideal technology for large-depth in situ stress measurement.

\section{Geological Core Ground Reorientation Technology}

\subsection{Theory of Geological Core Ground Reorientation Technology}

\subsubsection{Precondition of Geological Core Reorientation.} During the process of deep drilling and coring production, bending of the borehole will occur without exception due to geological and technological factors. Moreover, the axis of the core is always in line with that of the borehole under normal drilling conditions. Therefore, it is possible to characterize the bending state of the core column using the borehole incline-measure data. The geological core ground reorientation is based on the above conditions and uses known incline-measure data to calculate the other additional incline-measure related data. Further, the continuously linked inclinometry is carried out in reverse with an inclinometer calibration stage to reorientate the in situ orientation of the core.

\subsubsection{Spatial Spherical Geometry Model of Incline-Measure} Data. Figure 1 shows the spatial spherical coordinates of the upper $(A)$ and lower $(B)$ measuring points of single inclinemeasure data. $\mathrm{PP}^{\prime}$ is the upright diameter of the sphere,

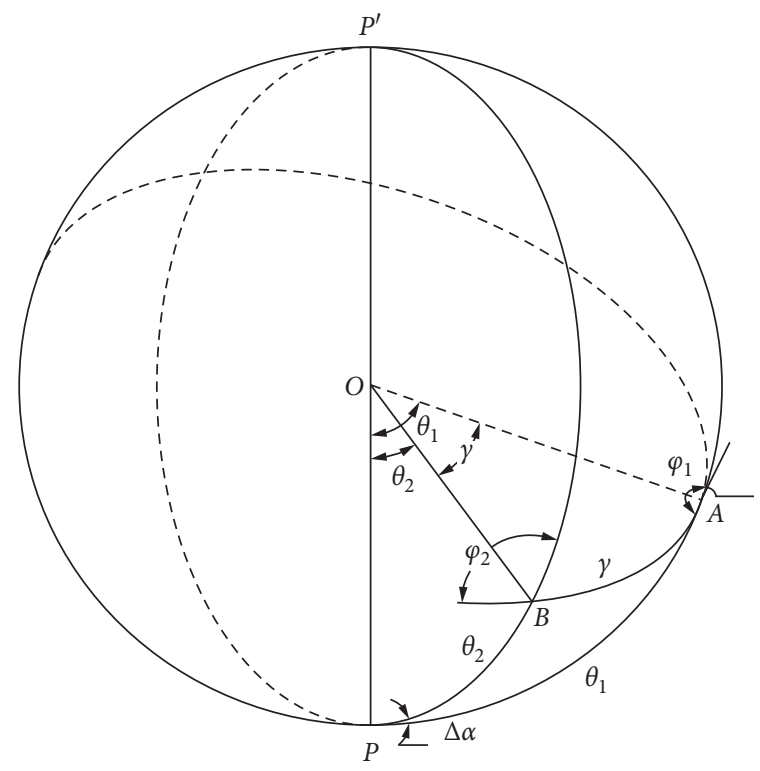

FIgURE 1: Mapping of incline-measure data in a spatial spherical coordinate.

$\mathrm{OP}^{\prime} \mathrm{AP}$ and $\mathrm{OP} \mathrm{BP}$ are two large upright circles, and $\mathrm{OAB}$ is the large inclined circle. $\mathrm{OA}$ and $\mathrm{OB}$ are the adjacent upper and lower measuring points of the borehole, $\theta_{1}$ and $\theta_{2}$ are zenith angles, $\gamma$ is the total bending angle, and $\Delta \alpha$ is the change value of azimuth between two large upright circles. $\varphi_{1}$ and $\varphi_{2}$, angles between the two upright large circles and the large inclined circle, are the special values of the end angle of the upper $(A)$ and lower $(B)$ measuring points. Thus, the three sides of the spherical triangle ABP are $\theta_{1}, \theta_{2}$, and $\gamma$, and the three angles are $\pi-\varphi_{1}, \varphi_{2}$, and $\Delta \alpha$. For the above parameters, if any three parameters are known, the other three parameters can be calculated according to the spherical triangle correlation.

\subsubsection{Geological Core Ground Reorientation Based on an} Inverse Process of Continuously Linked Inclinometry. Continuously linked inclinometry is the use of measuring tools to obtain the zenith angle $\theta_{i}$, zenith angle $\theta_{i+1}$, end angle $\varphi_{i}$, and end angle $\varphi_{i+1}\left(\Delta \varphi=\varphi_{i+1}-\varphi_{i}\right)$ at the upper and lower end of a measuring section of the borehole. After that, the change value of azimuth $\Delta \alpha$ can be calculated to orient the borehole. The inverse process is to calculate the total bending angle $\gamma$, end angle $\varphi_{1}$, and end angle $\varphi_{2}$ under the condition that the zenith angle $\theta_{1}$, zenith angle $\theta_{2}$, and azimuth change value $\Delta \alpha$ are known. Further, $\pi-\varphi_{1}, \varphi_{2}, \gamma$, and the other three parameters $\left(\theta_{1}, \theta_{2}\right.$, and $\left.\Delta \alpha\right)$ constitute the unique spherical triangle, as shown in Figure 1. According to the above six parameters $\left(\varphi_{1}, \varphi_{2}, \gamma, \theta_{1}, \theta_{2}\right.$, and $\left.\Delta \alpha\right)$, the in situ spatial posture of the core is restored using an inclinometer calibration stage.

2.2. Procedure of Geological Core Ground Reorientation Technology. Ground reorientation method of the nonorientation core includes the following steps. 
(1) Sampling: the fresh geological cores are collected from the drilling site or geological core library. The geological cores need to ensure that the structure is complete, the length-diameter ratio is greater than 5, the upper end is marked, and the sampling depth is precise. The cores whose fractures coincide with each other should be collected as much as possible to help improve the measurement accuracy.

(2) Collection and analysis of incline-measure data: the incline-measure data of the borehole are collected, including the borehole depth, zenith angle, and azimuth angle. Based on the borehole depth, the upper and lower ends of each core sample are matched with the corresponding zenith angles $\theta$ and azimuth angle $\alpha$. If the sampling point is between the adjacent incline-measure points, the zenith angles and azimuth angles of the upper and lower ends of each core sample can be obtained by mathematical interpolation or stereographic projection-spherical triangle method. Further, $\varphi_{1}, \varphi_{2}$, and $\gamma$ of the upper and lower ends of each core sample can be calculated by spherical trigonometric formula as follows:

$\left\{\begin{array}{l}\operatorname{ctg} \varphi_{2}=-\cos \theta_{2} \cdot \operatorname{ctg} \Delta \alpha+\operatorname{ctg} \theta_{1} \cdot \sin \theta_{2} \cdot \csc \Delta \alpha, \\ \operatorname{ctg}\left(\pi-\varphi_{1}\right)=-\cos \theta_{1} \cdot \operatorname{ctg} \Delta \alpha+c t g \theta_{2} \cdot \sin \theta_{1} \cdot \csc \Delta \alpha, \\ \cos \gamma=\cos \theta_{1} \cdot \cos \theta_{2}+\sin \theta_{1} \cdot \sin \theta_{2} \cos \Delta \alpha .\end{array}\right.$

(3) Reverse measurement and reorientation: the inclinometer calibration stage, inclinometer shell, core coaxial fixture, and small-diameter inclinometer or fixed-plate inclinometer are used together to restore the spatial posture of nonorientation cores. The small-diameter inclinometer or fixed-plate inclinometer is fixed in inclinometer calibration stage, and the upper section of the core is clamped into the core coaxial fixture first. The inclinometer calibration stage is then adjusted to calibrate the zenith angle and azimuth angle of the upper section of the core. After that, the core coaxial fixture is released, and the core and inclinometer are rotated axially until the end angles of the upper and lower section coincide with the calculated values. Further, the spatial posture of the core is locked, and a generatrix line is marked on the core in the vertical direction (the direction indicating the weight of the inclinometer). The generatrix line is the intersection line of the plane where the total bending angle is located and the core column surface. Finally, a horizontal ellipse is marked on the core column surface, and the north $(N)$ direction is also marked on the horizontal ellipse according to the azimuth angle, as shown in Figure 2.

\section{In Situ Stress Measurement after Reorientation}

3.1. Sample Processing for AE Test. All the geological cores of in situ stress measurement were collected from the ZK2

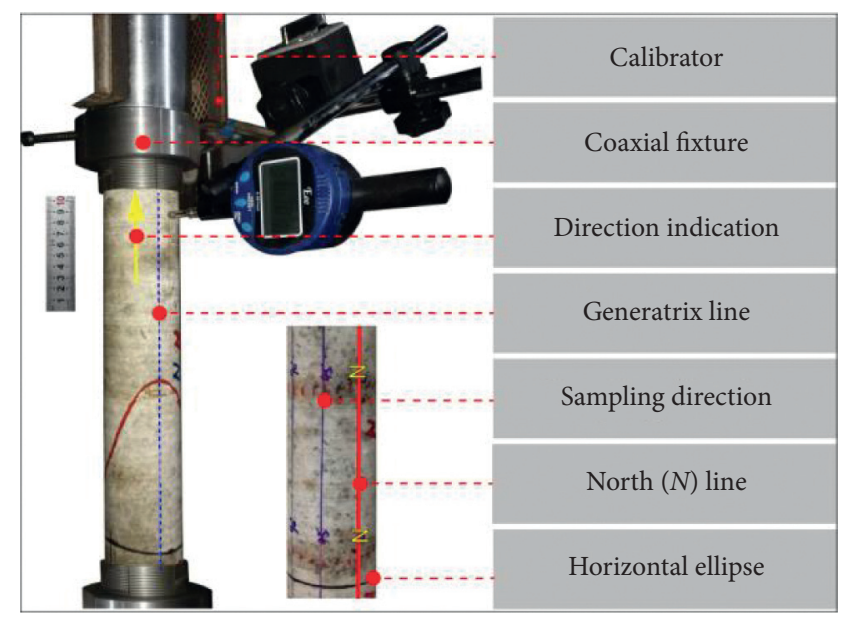

FIgURE 2: Reorientation of the nonorientation core.

geological borehole (the maximum borehole depth of $1040 \mathrm{~m}$ ) in the Xiangxi gold mine of Hunan Province, China, as shown in Figure 3. To grasp the distribution of in situ stress with depth and highlight the distribution of in situ stress in deep areas, geological cores with a diameter of $65 \mathrm{~mm}$ were taken from 200, 400, 600, 800, 900, and $1000 \mathrm{~m}$ depths of the borehole, respectively.

After the cores were reoriented accurately, the cylindrical samples for $\mathrm{AE}$ test were drilled from four directions of the cores, as shown in Figure 4. Three to five samples were drilled in the vertical direction, and its role was to determine the vertical stress according to the Kaiser point. Three to five samples were drilled, respectively, from three directions at $0^{\circ}$ (N), $45^{\circ}$, and $90^{\circ}$ on the horizontal ellipse plane of the core, to determine the direction and value of the horizontal maximum principal stress and the horizontal minimum principal stress according to the Kaiser points. To ensure the reliability of test results, samples were drilled and cut to a diameter of $25 \mathrm{~mm}$ and a height of $50 \mathrm{~mm}$. Both ends of each sample were carefully polished on the diamond grinding table.

3.2. Test Equipment. The loading instrument used in the test is American MTS 815 servocontrolled rigid material testing machine with the 793 control system, as shown in Figure 5(a). The testing machine has a maximum load of $2600 \mathrm{kN}$ and can precisely control load, displacement, and strain in a variety of modes. Besides, the test system is equipped with PCI-II multichannel AE instrument [30, 31]. Before the test, the above two instruments are modified synchronously, and the load data of the MTS 815 testing machine are introduced into the AE instrument as external parameter signals, as shown in Figure 5(b). Thus the AE events and the corresponding stress values can be simultaneously collected by the AE instrument at a megahertzlevel rate, which improves the accuracy of judgment of the Kaiser point.

3.3. Test Methods and Parameter Settings. The purpose of the $\mathrm{AE}$ test is to stimulate $\mathrm{AE}$ signals of rock samples by uniaxial compressive loading and then identify and 


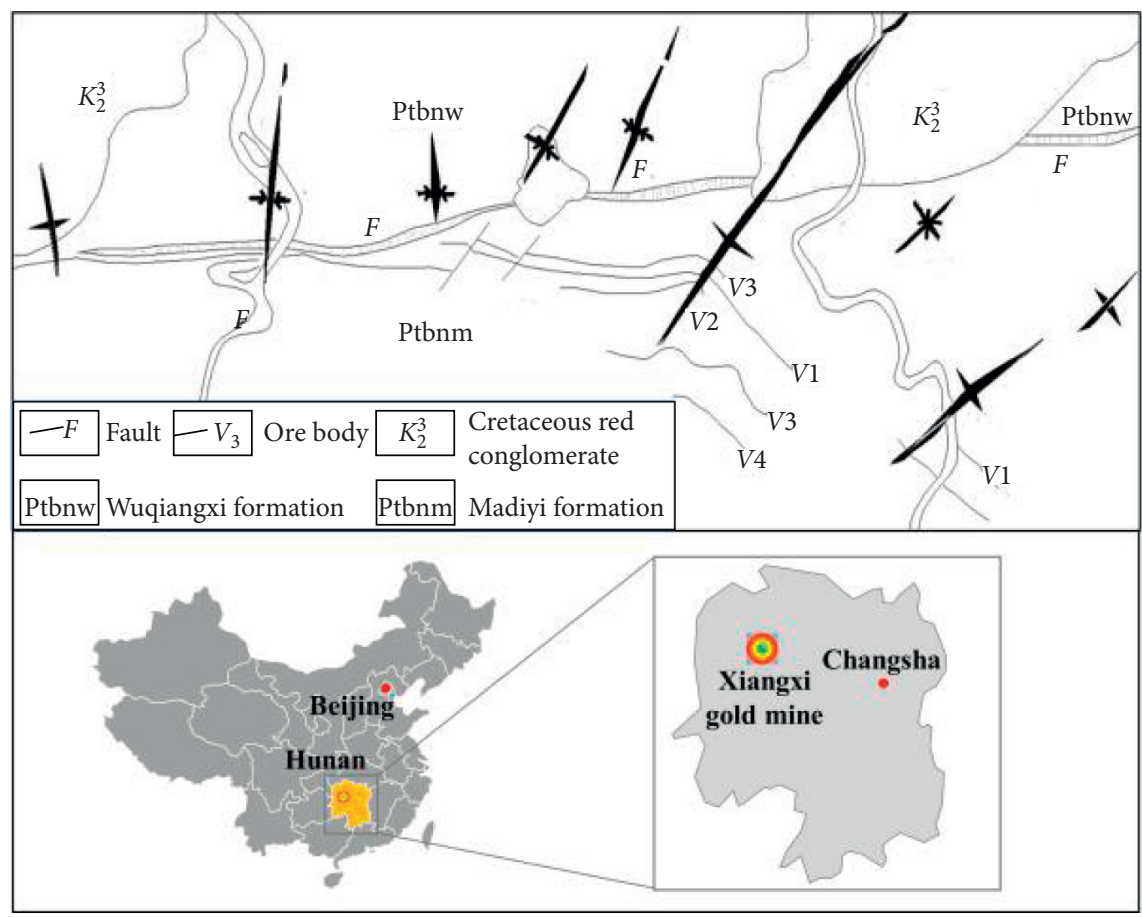

Figure 3: Schematic diagram of the structural geology of Xiangxi gold mine.

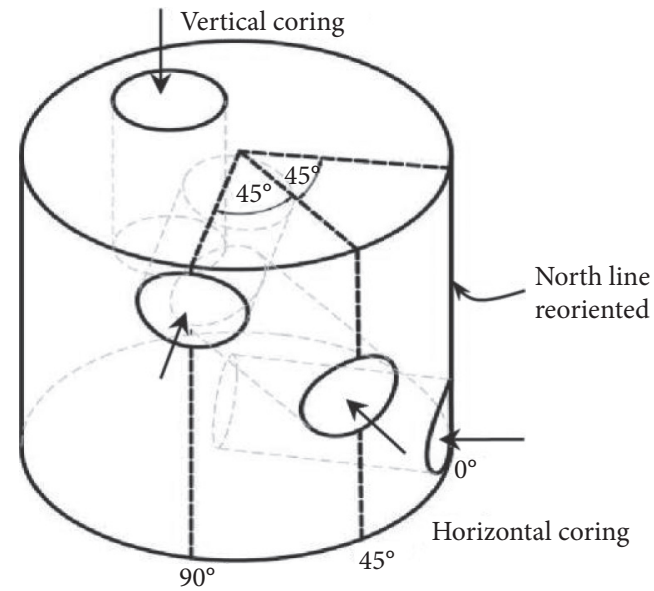

Figure 4: Four-direction sampling of reorientation cores.

determine the Kaiser points corresponding to in situ stress in AE signals. The displacement rate control mode of MTS testing machine was adopted in the test. The loading speed was set at $0.1 \mathrm{~mm} / \mathrm{min}$ under the graded cyclic loading state. The first-level stress of cyclic loading should be higher than the predicted in situ stress. Moreover, the dual-channel data acquisition mode of the AE instrument was adopted and the two AE probes (resonance frequency of $20-400 \mathrm{kHz}$ ) were placed on the opposite side of the sample. The preamplifier of the AE instrument was set to $40 \mathrm{~dB}$, the noise threshold was $40 \mathrm{~dB}$, and the AE sampling frequency is $1 \mathrm{MHz}$. In addition, the coupling agent was applied to the contact surface between the test sample and the AE probe, to ensure that the AE signal can be well received; a thin layer of petrolatum was applied at the interface between the press head and the test sample, to reduce the effect of end noise on the $\mathrm{AE}$ test results.

Figure 5(c) shows that both the loading value and the AE signals are collected simultaneously on the same time axis during the loading process. The mutation point of AE signal is well matched to the external load for the identification of Kaiser point and the corresponding stress.

\section{Results and Discussion}

4.1. Calculation and Analysis of In Situ Stress. According to the above AE test method, the initial Kaiser points of samples drilling from four directions are determined, and their corresponding loads are found, as shown in Figure 6. To ensure the validity of the test results, a minimum of 15 samples per depth were taken for AE test, and the average value of the results after removing astronomical deviation data is taken as the Kaiser stress, as shown in Table 1.

The Kaiser stress in the vertical direction in Table 1 is regarded as the vertical stress corresponding to the buried depth. The three Kaiser stresses in the horizontal direction $\left(0^{\circ}, 45^{\circ}\right.$, and $\left.90^{\circ}\right)$ in Table 1 are taken into the plane stress calculation equation (2) to calculate the magnitude and direction of the horizontal maximum and horizontal minimum principal stress [29], as shown in Table 2. 

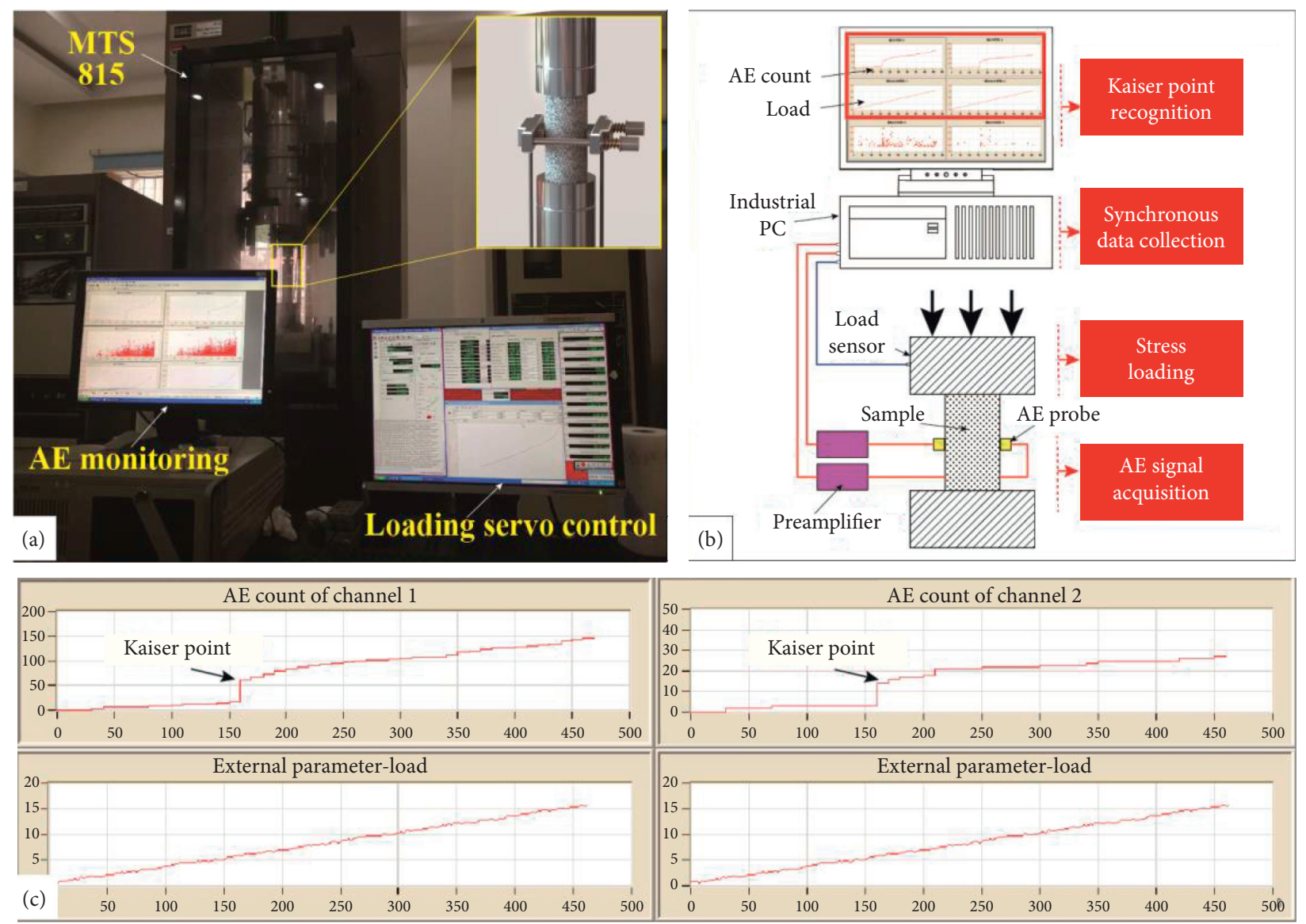

Figure 5: Test equipment. (a) MTS 815 material testing machine, (b) AE test schematic, and (c) identification of Kaiser point.
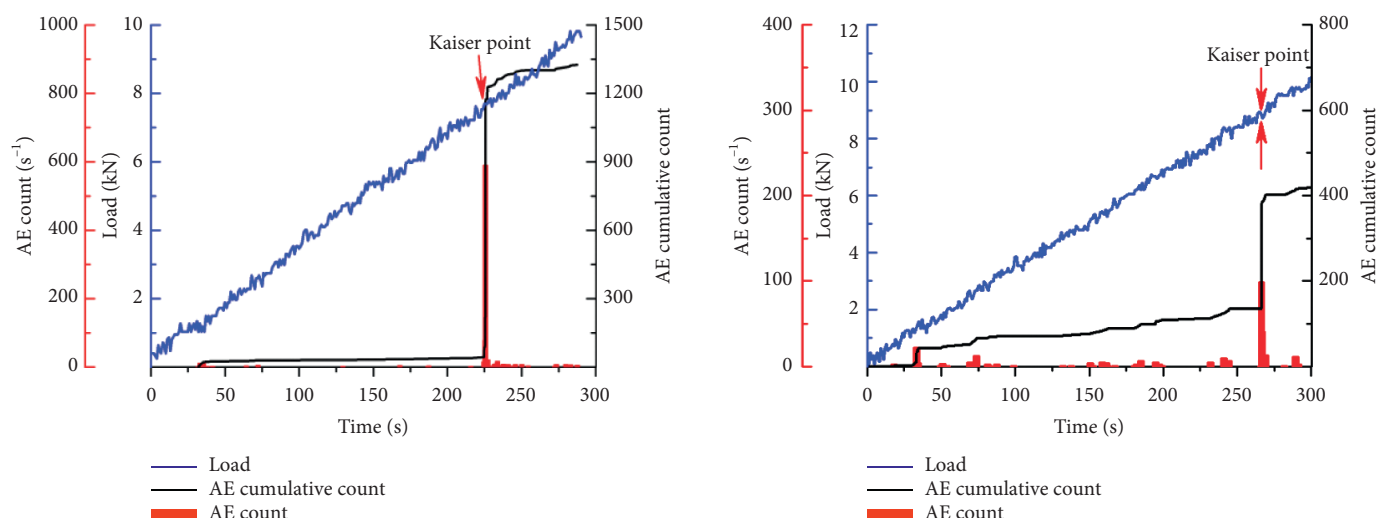

(a1)
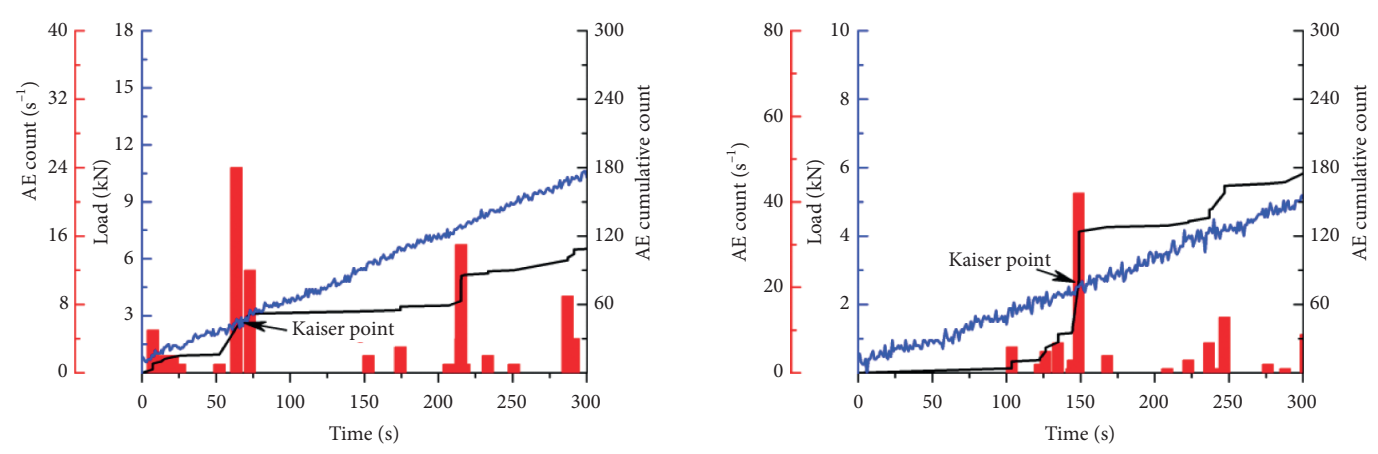

Load
AE cumulative count
AE count

— L L AE cumulative count

(a)

Figure 6: Continued. 

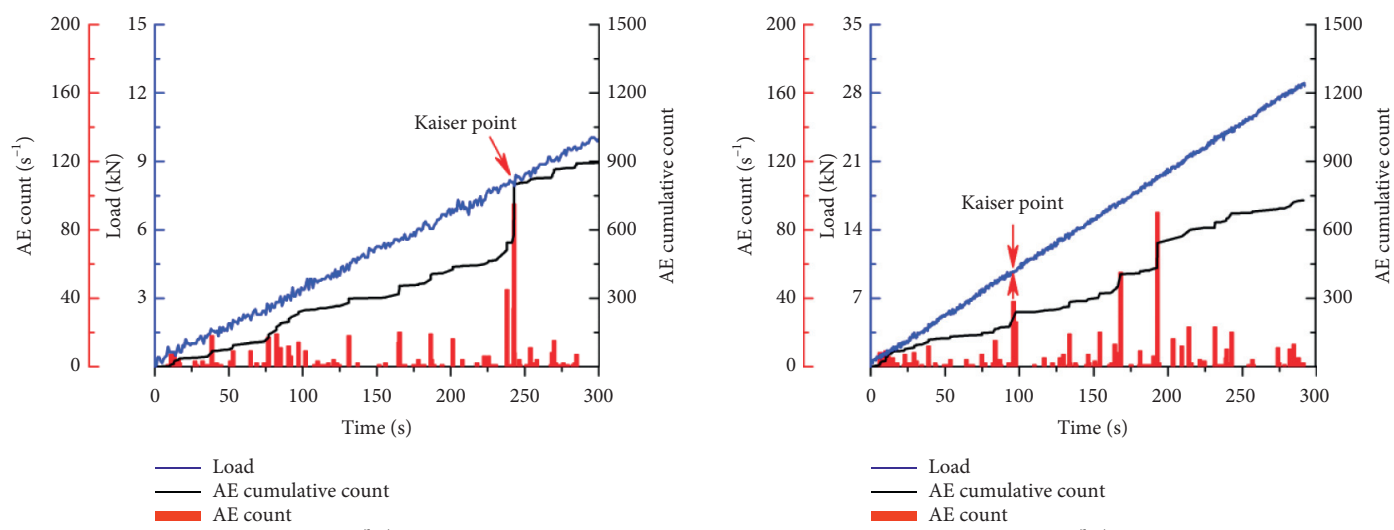

(b1)

(b2)
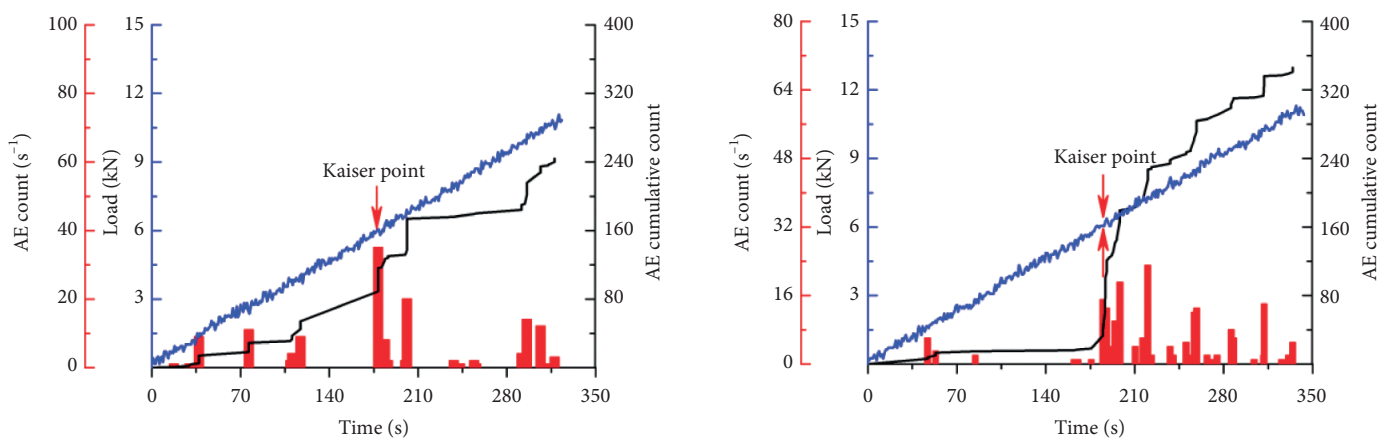

_ Load

(b3)

— $\mathrm{AE}$ cumulative count

AE count

AE count

(b4)

(b)
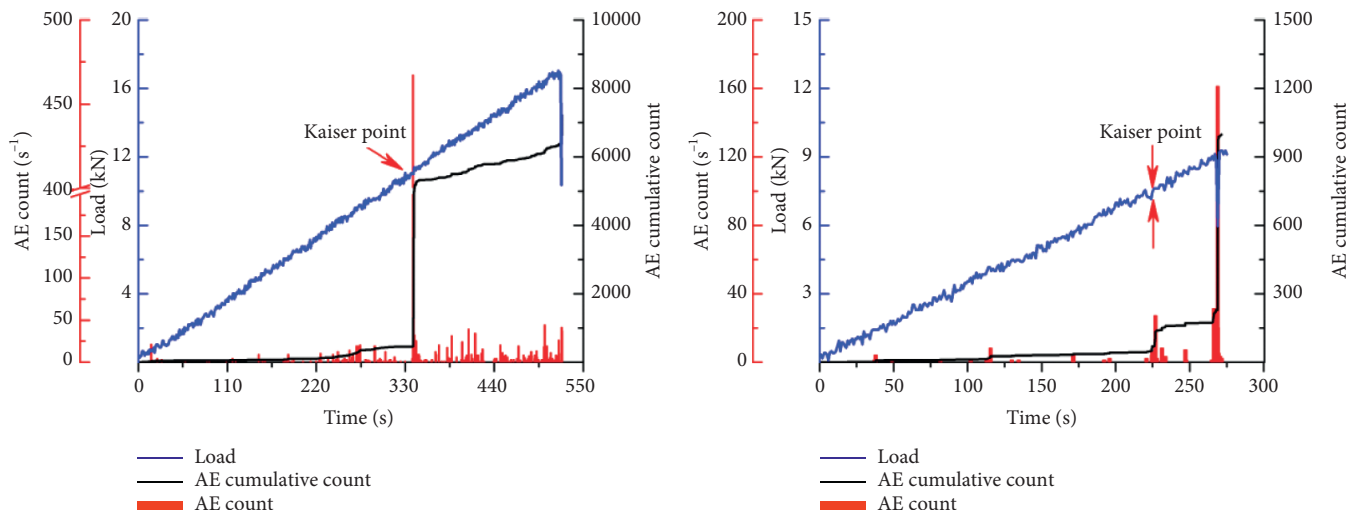

(c1)

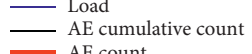

- AE count
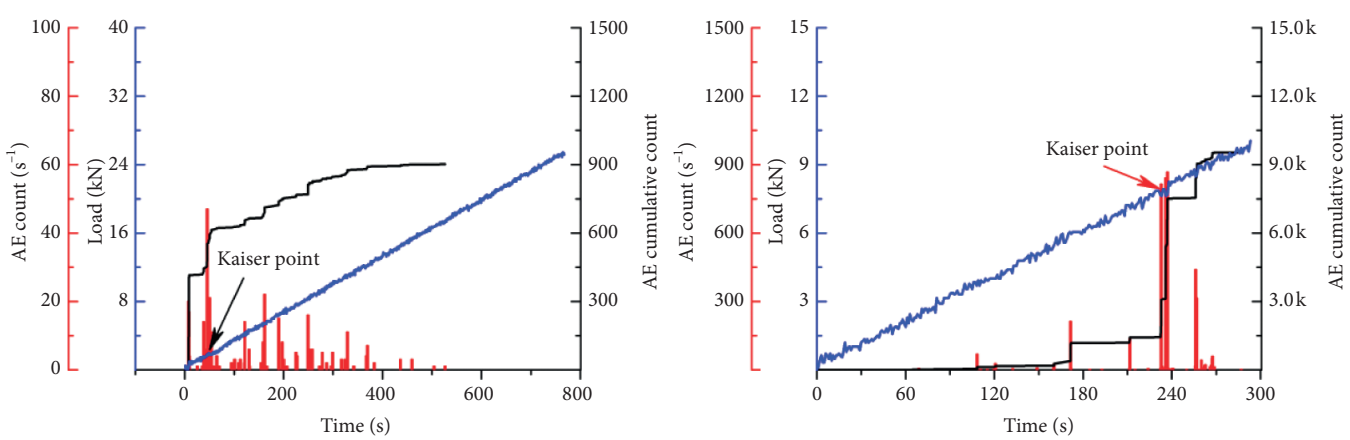

Load
AE cumulative count
AE count

Load
AE cumulative count
AE count

(c3)

(c4)

(c)

Figure 6: Continued. 

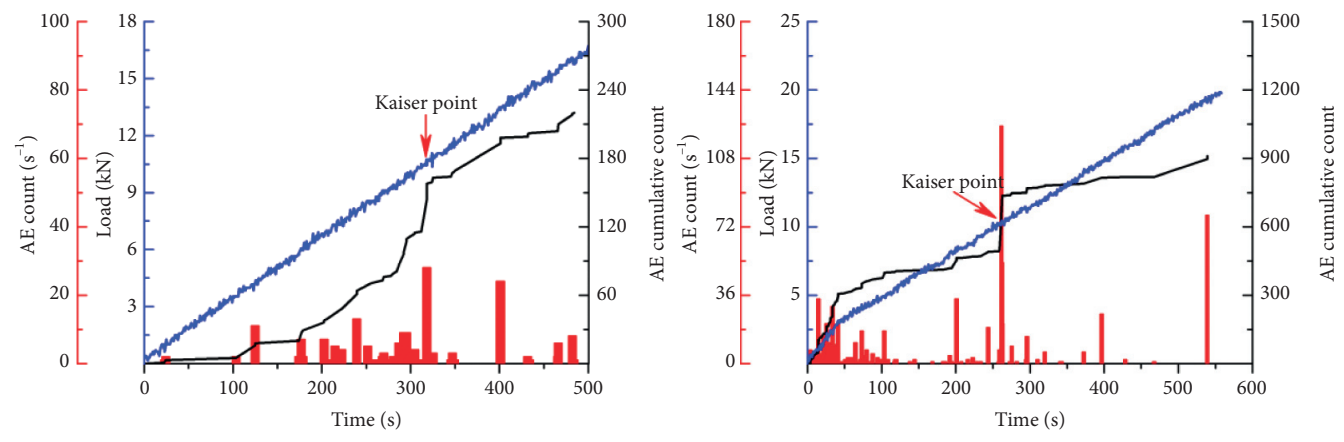

Load
AE cumulative count

$\mathrm{AE}$ count

(d1)

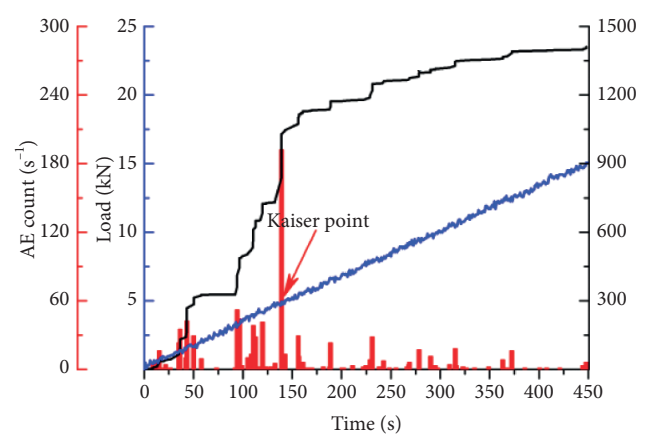

L Load

_- AE cumulative count

(d3)
Load

$\mathrm{AE}$ cumulative count

(d2)

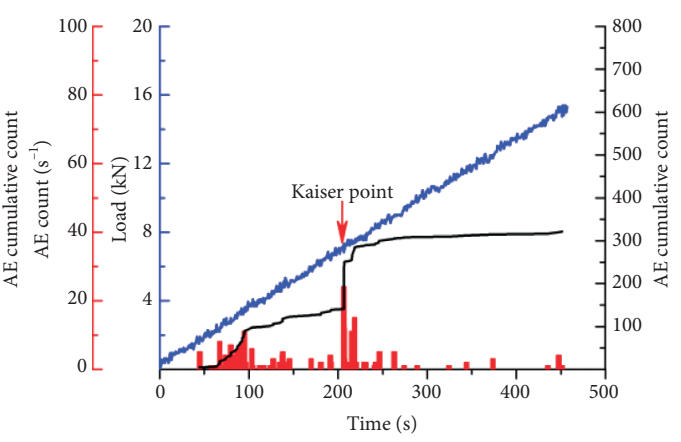

_ Load

AE cumulative count

AE count

(d4)

(d)

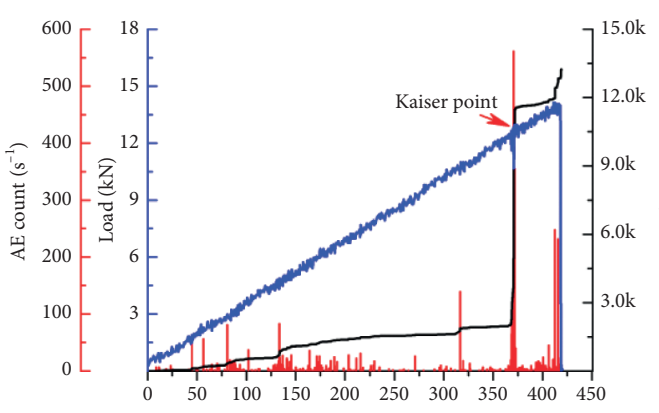

Time (s)

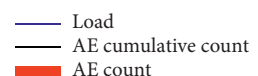

(e1)

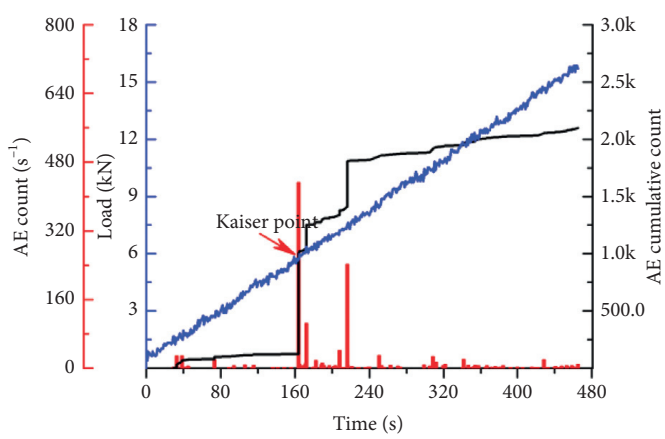

L Load

_- AE cumulative count

AE count

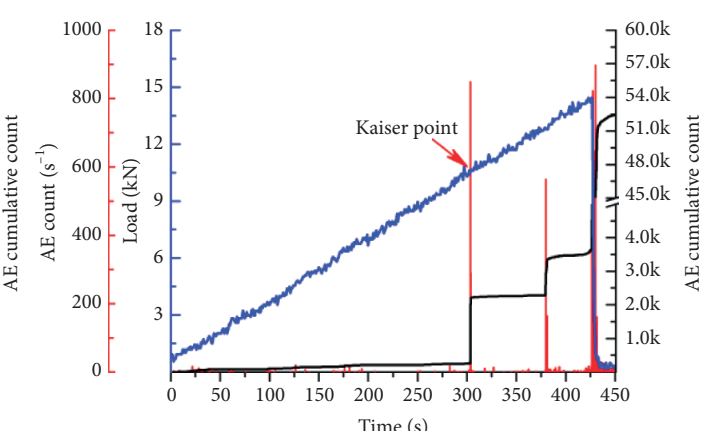

Load
AE cumulative count

(e2)

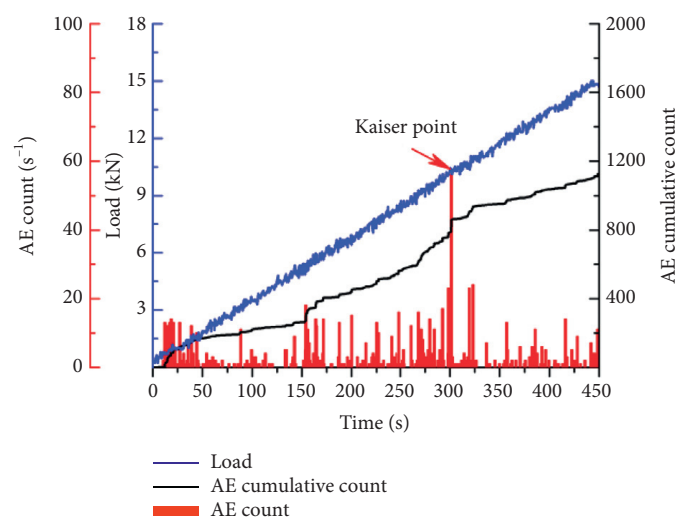

(e4)

(e)

Figure 6: Continued. 

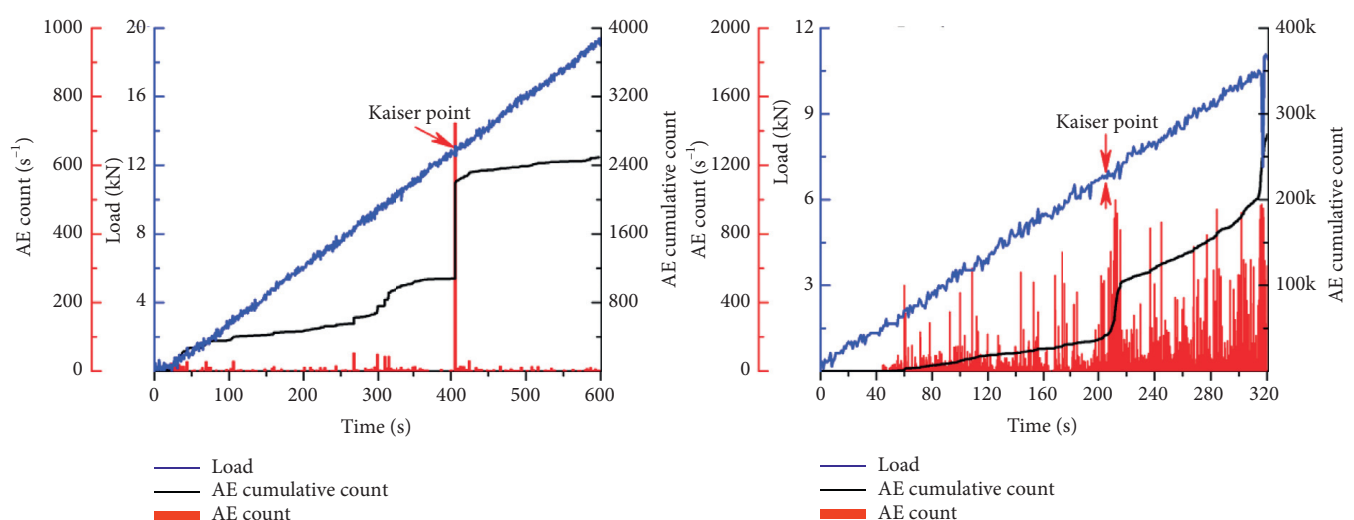

$(\mathrm{fl})$
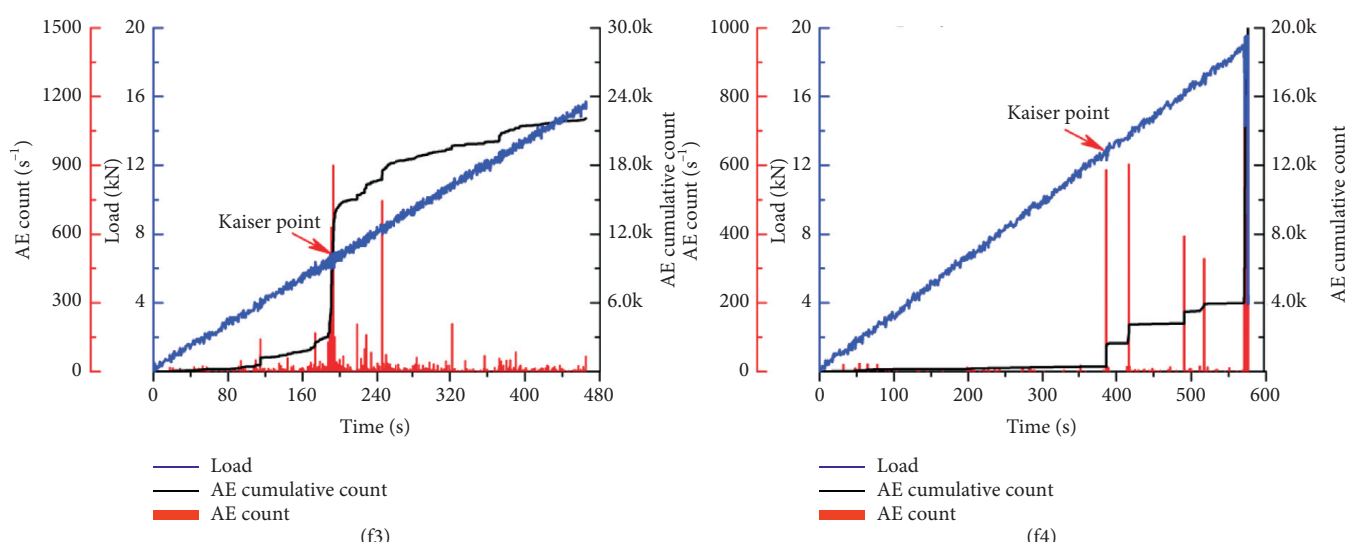

(f)

Figure 6: Representative Kaiser point results at each test depth. (a1) Horizontal $0^{\circ}$ at $200 \mathrm{~m}$ depth, (a2) horizontal $45^{\circ}$ at $200 \mathrm{~m}$ depth, (a3) horizontal $90^{\circ}$ at $200 \mathrm{~m}$ depth, (a4) vertical direction at $200 \mathrm{~m}$ depth, (b1) horizontal $0^{\circ}$ at $400 \mathrm{~m}$ depth, (b2) horizontal $45^{\circ}$ at $400 \mathrm{~m}$ depth, (b3) horizontal $90^{\circ}$ at $400 \mathrm{~m}$ depth, (b4) vertical direction at $400 \mathrm{~m}$ depth, (c1) horizontal $0^{\circ}$ at $600 \mathrm{~m}$ depth, (c2) horizontal $45^{\circ}$ at $600 \mathrm{~m}$ depth, (c3) horizontal $90^{\circ}$ at $600 \mathrm{~m}$ depth, (c4) vertical direction at $600 \mathrm{~m}$ depth, (d1) horizontal $0^{\circ}$ at $800 \mathrm{~m}$ depth, (d2) horizontal $45^{\circ}$ at $800 \mathrm{~m}$ depth, (d3) horizontal $90^{\circ}$ at $800 \mathrm{~m}$ depth, (d4) vertical direction at $800 \mathrm{~m}$ depth, (e1) horizontal $0^{\circ}$ at $900 \mathrm{~m}$ depth, (e2) horizontal $45^{\circ}$ at $900 \mathrm{~m}$ depth, (e3) horizontal $90^{\circ}$ at $900 \mathrm{~m}$ depth, (e4) vertical direction at $900 \mathrm{~m}$ depth, (f1) horizontal $0^{\circ}$ at $1000 \mathrm{~m}$ depth, (f2) horizontal $45^{\circ}$ at $1000 \mathrm{~m}$ depth, (f3) horizontal $90^{\circ}$ at $1000 \mathrm{~m}$ depth, and (f4) vertical direction at $1000 \mathrm{~m}$ depth.

$$
\left\{\begin{array}{l}
\sigma_{H}=\frac{1}{2}\left(\sigma_{I}+\sigma_{I I I}\right)+\frac{1}{2 \cos 2 \beta}\left(\sigma_{I}-\sigma_{I I I}\right) \\
\sigma_{h}=\frac{1}{2}\left(\sigma_{I}+\sigma_{I I I}\right)-\frac{1}{2 \cos 2 \beta}\left(\sigma_{I}-\sigma_{I I I}\right) \\
\tan 2 \beta=\frac{2 \sigma_{I I}-\sigma_{I}-\sigma_{I I I}}{\sigma_{I}-\sigma_{I I I}}
\end{array}\right.
$$

where $\sigma_{I}, \sigma_{I I}$, and $\sigma_{I I I}$ are measured stresses at $0^{\circ}, 45^{\circ}$, and $90^{\circ}$ from clockwise direction due north, respectively; $\sigma_{H}$ is the horizontal maximum principal stress, $\sigma_{h}$ is the horizontal minimum principal stress, and $\beta$ is the angle between the direction of horizontal maximum principal stress and the north direction, which is positive when turned counterclockwise to the north direction.

4.2. Distribution and Variation of In Situ Stress. Figure 7(a) and Table 2 show that the in situ stress in the drilling area is dominated by horizontal tectonic stress, especially at the borehole depth of less than $600 \mathrm{~m}$. With the further increase in the depth, the dominant effect of the horizontal tectonic stress decreases, while the effect of vertical stress increases. In addition, the horizontal maximum principal stress increases with borehole depth. The horizontal minimum principal stress also increases with borehole depth, with a higher value near $400 \mathrm{~m}$ depth. The abnormal point of in situ stress may be related to the implicit geological structure in the local area.

The azimuth of the horizontal maximum principal stress at different depths is consistent, all of which are near the north, distributing between $\mathrm{N} 5^{\circ} \mathrm{W}-\mathrm{N} 18^{\circ} \mathrm{E}$, as shown in Figure 7(b).

Figure $7(\mathrm{c})$ shows that the vertical principal stress increases linearly with the borehole depth, which is consistent with the gravitational stress at the corresponding buried depth.

The linear regression analysis is performed on the stress values in Figure 7(a), and the calculation formula of the in situ stress with depth in the drilling area can be obtained: 
TABle 1: Kaiser stress of AE tests.

\begin{tabular}{|c|c|c|c|c|c|c|c|c|}
\hline \multirow[b]{3}{*}{ Borehole depth (m) } & \multirow{2}{*}{\multicolumn{2}{|c|}{$\begin{array}{l}\text { Kaiser stress in the vertical } \\
\text { direction }(\mathrm{MPa})\end{array}$}} & \multicolumn{6}{|c|}{ Kaiser stress in the horizontal direction $(\mathrm{MPa})$} \\
\hline & & & \multicolumn{2}{|c|}{$\sigma_{I}\left(0^{\circ}\right)$} & \multicolumn{2}{|c|}{$\sigma_{I I}\left(45^{\circ}\right)$} & \multicolumn{2}{|c|}{$\sigma_{I I I}\left(90^{\circ}\right)$} \\
\hline & Actual value & Average value & Actual value & Average value & Actual value & $\begin{array}{c}\text { Average } \\
\text { value }\end{array}$ & Actual value & Average value \\
\hline \multirow{4}{*}{200} & 5.26 & \multirow{4}{*}{5.10} & 13.94 & \multirow{4}{*}{18.27} & 18.00 & \multirow{4}{*}{16.35} & 4.29 & \multirow{4}{*}{5.10} \\
\hline & 5.52 & & 19.75 & & 14.11 & & 5.33 & \\
\hline & 4.52 & & 22.14 & & 15.62 & & 5.29 & \\
\hline & - & & 17.23 & & 17.69 & & 5.48 & \\
\hline \multirow{4}{*}{400} & 11.09 & \multirow{4}{*}{12.35} & 21.72 & \multirow{4}{*}{20.02} & 18.73 & \multirow{4}{*}{18.71} & 9.44 & \multirow{4}{*}{11.96} \\
\hline & 13.10 & & 14.75 & & 17.61 & & 13.44 & \\
\hline & 12.85 & & 17.51 & & 21.97 & & 15.92 & \\
\hline & - & & 26.08 & & 16.52 & & 9.03 & \\
\hline \multirow{4}{*}{600} & 16.60 & \multirow{4}{*}{16.58} & 25.24 & \multirow{4}{*}{22.47} & 16.60 & \multirow{4}{*}{13.00} & 4.16 & \multirow{4}{*}{5.55} \\
\hline & 16.60 & & 21.63 & & 14.41 & & 8.63 & \\
\hline & 16.55 & & 23.65 & & 10.91 & & 4.98 & \\
\hline & - & & 19.34 & & 10.09 & & 4.42 & \\
\hline \multirow{4}{*}{800} & 16.61 & \multirow{4}{*}{19.91} & 22.61 & \multirow{4}{*}{23.06} & 15.54 & \multirow{4}{*}{20.15} & 9.41 & \multirow{4}{*}{9.73} \\
\hline & 27.62 & & 22.32 & & 19.88 & & 8.75 & \\
\hline & 15.51 & & 25.06 & & 18.59 & & 11.95 & \\
\hline & - & & 22.25 & & 26.59 & & 8.80 & \\
\hline \multirow{4}{*}{900} & 17.80 & \multirow{4}{*}{23.75} & 30.08 & \multirow{4}{*}{24.64} & 20.88 & \multirow{4}{*}{21.33} & 11.26 & \multirow{4}{*}{11.64} \\
\hline & 22.76 & & 22.10 & & 23.87 & & 12.19 & \\
\hline & 30.69 & & 24.31 & & 18.99 & & 13.04 & \\
\hline & - & & 22.09 & & 21.58 & & 10.07 & \\
\hline & 26.52 & & 32.57 & & 15.52 & & 15.65 & \\
\hline 1000 & 21.80 & 2560 & 24.80 & & 17.59 & & 10.28 & 1341 \\
\hline 1000 & 28.76 & 25.69 & 25.30 & 26.12 & 19.49 & 18.65 & 13.40 & 13.41 \\
\hline & - & & 21.80 & & 21.99 & & 14.33 & \\
\hline
\end{tabular}

TABLe 2: Magnitude and direction of principal stress.

\begin{tabular}{lccccc}
\hline $\begin{array}{l}\text { Measuring point } \\
\text { depth }(\mathrm{m})\end{array}$ & $\begin{array}{c}\text { Vertical principal } \\
\text { stress } \sigma_{v}(\mathrm{MPa})\end{array}$ & $\begin{array}{c}\text { Gravitational stress } \\
\sigma_{G}(\mathrm{MPa})\end{array}$ & $\begin{array}{c}\text { Horizontal maximum } \\
\text { principal stress } \sigma_{H} \\
(\mathrm{MPa})\end{array}$ & $\begin{array}{c}\text { Horizontal minimum } \\
\text { principal stress } \sigma_{h} \\
(\mathrm{MPa})\end{array}$ & $\begin{array}{c}\text { Horizontal maximum } \\
\text { principal stress azimuth } \beta \\
\left({ }^{\circ}\right)\end{array}$ \\
\hline 200 & 5.10 & 5.50 & 19.75 & 3.62 & 17.66 \\
400 & 12.35 & 11.00 & 20.85 & 11.13 & 17.01 \\
600 & 16.58 & 16.50 & 22.53 & 5.49 & -3.40 \\
800 & 19.91 & 22.00 & 24.04 & 10.75 & 14.70 \\
900 & 23.75 & 24.75 & 25.38 & 13.90 & 13.07 \\
1000 & 25.69 & 27.50 & 26.22 & 13.98 & -4.98 \\
\hline
\end{tabular}

$$
\left\{\begin{array}{l}
\sigma_{V}=0.0262 h \\
\sigma_{H}=0.0082 h+17.79 \\
\sigma_{h}=0.0084 h+3.38
\end{array}\right.
$$

where $\sigma_{v}$ is the predicted vertical principal stress, MPa; $\sigma_{H}$ is the predicted horizontal maximum principal stress, $\mathrm{MPa} ; \sigma_{h}$ is the predicted horizontal minimum principal stress, $\mathrm{MPa}$; and $h$ is the depth, $m$.

4.3. Comparative Verification of Measurement Accuracy. In order to analyze the accuracy of the measured in situ stress comparatively, Xiangxi gold mine carried out verification in situ stress measurement in the underground mine with the stress relief method. The measurements were performed at a depth of $655-958 \mathrm{~m}$ in the mine, using the Swedish LUT rock triaxial in situ stress measurement system, as shown in Figure 8.

The magnitude and direction of the in situ stresses at the four measurement points were obtained from the LUT in situ stress calculation program, as shown in Table 3. Besides, based on the stress components obtained during stress relief, planar stress calculations were performed to solve $\sigma_{H}, \sigma_{h}$, and $\sigma_{v}$ at each measurement point, as shown in Table 4. Meanwhile, (3) fitted by the AE method was also used to calculate the $\mathrm{AE}$ in situ stresses at the four measurement points, which were listed in Table 4 for comparative analysis.

Tables 3 and 4 show that the in situ stress measured by the stress relief method has the following distribution characteristics: 


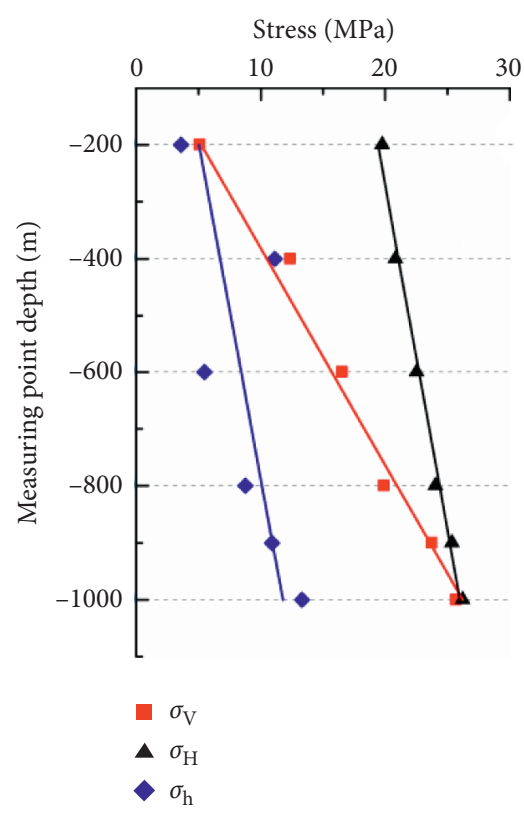

(a)

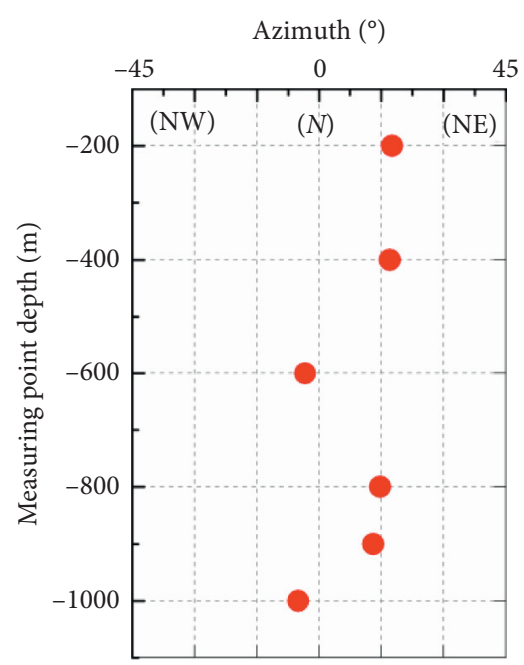

(b)

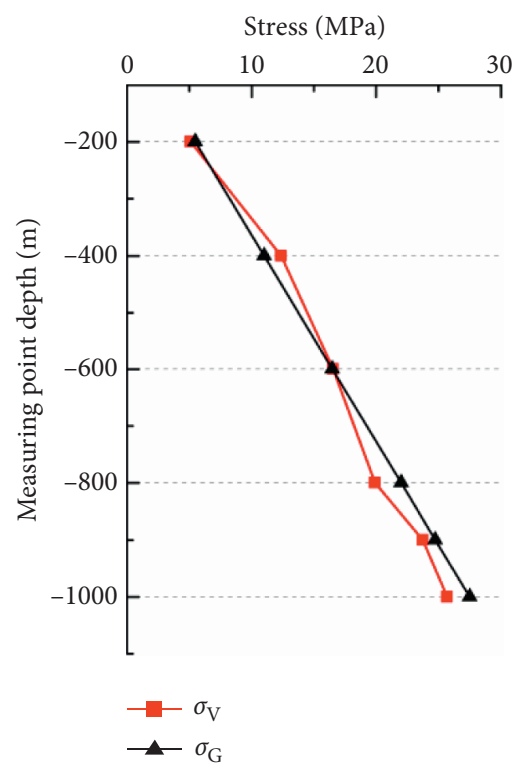

(c)

Figure 7: Distribution and variation of in situ stress. (a) $\sigma_{v}, \sigma_{H}$, and $\sigma_{h}$; (b) azimuth $\beta$; (c) $\sigma_{v}$ and $\sigma_{G}$.
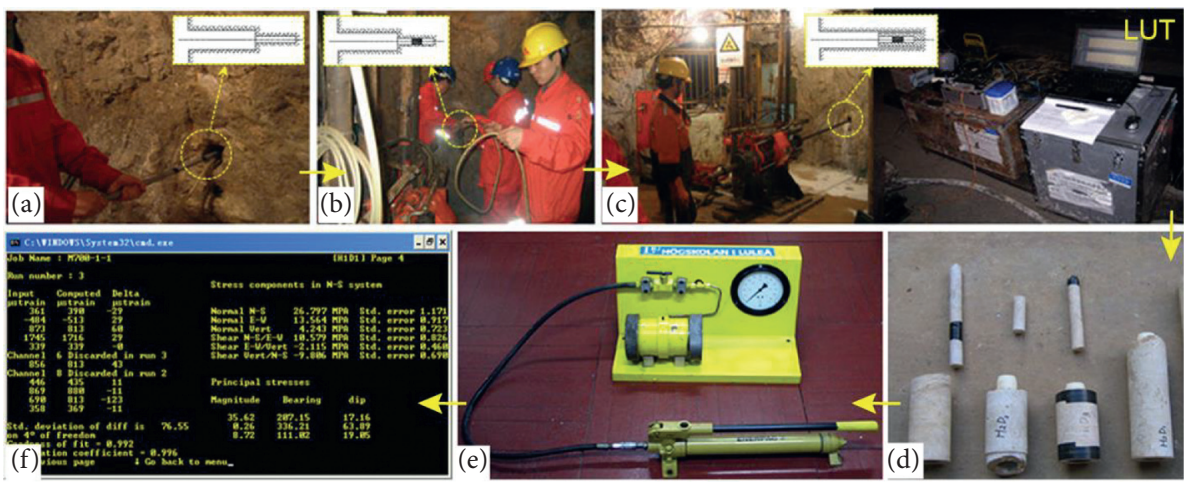

FIGURE 8: Stress relief process. (a) Drilling and cleaning, (b) installing strain gauge probe, (c) stress relief and data acquisition, (d) getting the core tube, (e) confining pressure calibration, (f) and in situ stress calculation.

(1) The dip angle of the maximum principal stress $(\sigma 1)$ generally increases with depth, as shown in Table 3 . The dip angle of $\sigma 1$ at a depth of $655 \mathrm{~m}$ is $14.17^{\circ}$, indicating that the $\sigma 1$ is a significant horizontal stress. When the depth increases to $756-765 \mathrm{~m}$, the dip angle of $\sigma 1$ increases to $24.47^{\circ}-26.91^{\circ}$, indicating that the $\sigma 1$ is near horizontal stress. Until the depth increases to $958 \mathrm{~m}$, the dip angle of $\sigma 1$ reaches $47.34^{\circ}$, indicating that the $\sigma 1$ is inclined stress. The trend of dip angle of $\sigma 1$ shows that the in situ stress changes from being dominated by horizontal stress to being dominated by vertical stress with depth, which is consistent with the resulting trend of the AE method. (2) The azimuth of $\sigma 1$ is $\mathrm{N} 41.16^{\circ} \mathrm{W}-\mathrm{N} 24^{\circ} \mathrm{E}$, which is close to the azimuth measured by the AE method, pointing to the near north direction, as shown in Figure 9. (3) The vertical stress $\left(\sigma_{V}\right)$ measured by the stress relief method increases with depth, as shown in Table 4, which is also consistent with the resulting trend of the AE method.

In summary, the measurement results of the reorientation core $\mathrm{AE}$ method and stress relief method are in good agreement. In particular, there is consistency in the change of maximum principal stress, the azimuth of maximum principal stress, and the change of vertical stress, which shows that the reorientation core AE method is reliable. Certainly, Table 4 shows that there is some deviation in the values of $\sigma_{H}, \sigma_{h}$, and $\sigma_{v}$ obtained by the two types of 
TABLE 3: In situ stress results of the stress relief method.

\begin{tabular}{|c|c|c|c|c|c|c|c|c|c|c|}
\hline \multirow[b]{2}{*}{ No. } & \multirow[b]{2}{*}{$\begin{array}{l}\text { Depth } \\
\text { (m) }\end{array}$} & \multicolumn{3}{|c|}{ Maximum principal stress $\sigma_{1}$} & \multicolumn{3}{|c|}{ Intermediate principal stress $\sigma_{2}$} & \multicolumn{3}{|c|}{ Minimum principal stress $\sigma_{3}$} \\
\hline & & $\begin{array}{l}\text { Magnitude } \\
\quad(\mathrm{MPa})\end{array}$ & $\begin{array}{c}\text { Azimuth } \\
\left({ }^{\circ}\right)\end{array}$ & $\operatorname{Dip}\left({ }^{\circ}\right)$ & $\begin{array}{l}\text { Magnitude } \\
\text { (MPa) }\end{array}$ & $\begin{array}{c}\text { Azimuth } \\
\left({ }^{\circ}\right)\end{array}$ & $\operatorname{Dip}\left({ }^{\circ}\right)$ & $\begin{array}{l}\text { Magnitude } \\
(\mathrm{MPa})\end{array}$ & $\underset{\left({ }^{\circ}\right)}{\text { Azimuth }}$ & $\operatorname{Dip}\left({ }^{\circ}\right)$ \\
\hline $1 \#$ & 655 & 29.67 & 24.06 & 14.17 & 11.53 & 285.31 & 31.09 & 2.74 & 135.31 & 55.15 \\
\hline $2 \#$ & 756 & 32.74 & 332.15 & 26.91 & 17.07 & 77.15 & 26.69 & 1.11 & 204.56 & 50.39 \\
\hline $3 \#$ & 765 & 32.27 & 322.84 & 24.47 & 17.67 & 70.18 & 33.22 & 0.58 & 204.04 & 46.62 \\
\hline 4\# & 958 & 39.35 & 318.84 & 47.34 & 28.10 & 94.19 & 33.23 & 10.67 & 200.73 & 23.47 \\
\hline
\end{tabular}

TABle 4: Comparison of the results of stress relief method and AE method.

\begin{tabular}{|c|c|c|c|c|c|c|c|c|c|}
\hline \multirow{2}{*}{ Depth } & \multicolumn{3}{|c|}{$\sigma_{H}(\mathrm{MPa})$} & \multicolumn{3}{|c|}{$\sigma_{h}(\mathrm{MPa})$} & \multicolumn{3}{|c|}{$\sigma_{v}(\mathrm{MPa})$} \\
\hline & Stress relief & $\mathrm{AE}$ & Deviation & Stress relief & $\mathrm{AE}$ & Deviation & Stress relief & $\mathrm{AE}$ & Deviation \\
\hline 655 & 28.25 & 23.16 & 0.18 & 8.99 & 8.88 & 0.01 & 6.70 & 17.16 & 0.61 \\
\hline 756 & 27.76 & 23.99 & 0.14 & 12.35 & 9.73 & 0.21 & 10.81 & 19.81 & 0.45 \\
\hline 765 & 28.57 & 24.06 & 0.16 & 10.80 & 9.81 & 0.09 & 11.15 & 20.04 & 0.44 \\
\hline 958 & 32.38 & 25.65 & 0.21 & 14.32 & 11.43 & 0.20 & 31.42 & 25.10 & 0.20 \\
\hline
\end{tabular}

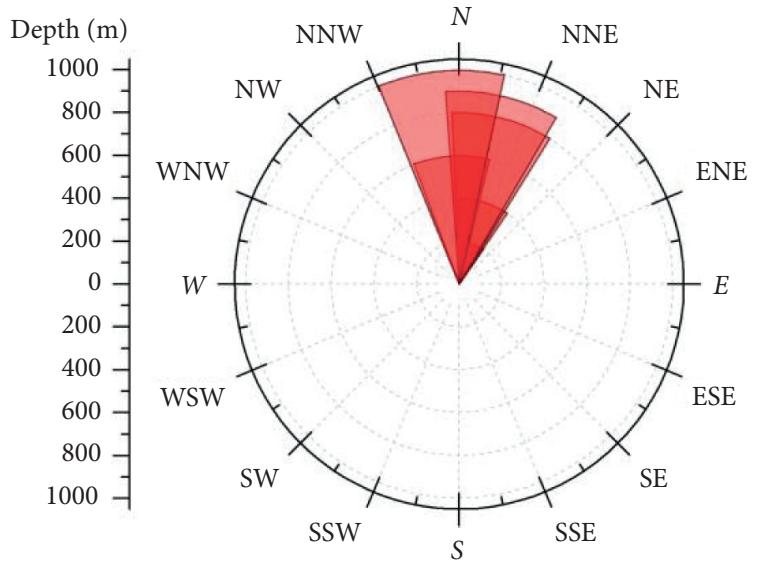

(a)

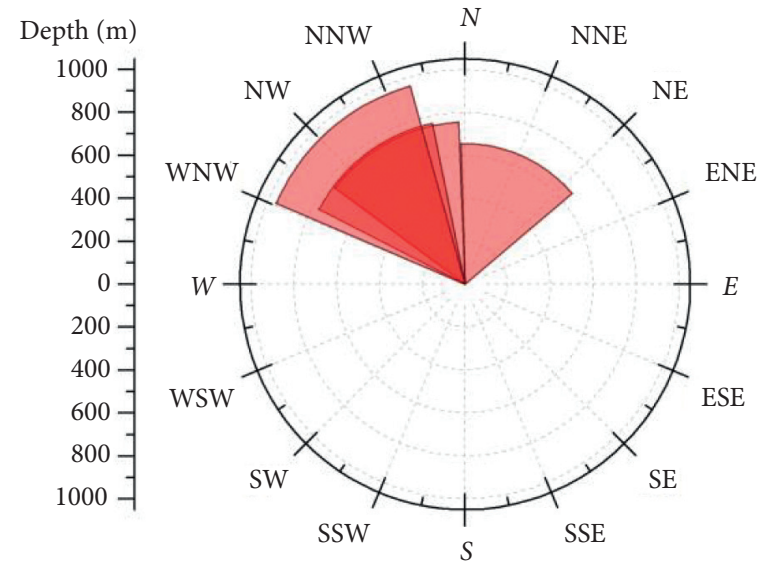

(b)

FIgURE 9: Azimuth of maximum principal stress. (a) Azimuth measured by AE method and (b) azimuth measured by stress relief method.

methods, which is mainly due to the difference in geological structure (shown in Figure 3 ) of the sampling points and the fact that the shear stresses were not taken into account in the reorientation core $\mathrm{AE}$ method.

\section{Conclusion}

In this study, an innovative deep in situ stress measurement method capable of the geological core ground reorientation technology and the AE technology was developed. With this method, the distribution of deep in situ stress of an overkilometer-deep shaft in Xiangxi gold mine was investigated. Meanwhile, to analyze the accuracy of the measured in situ stress comparatively, the stress relief measurements were performed. The following are the conclusions drawn from this study:

(1) The geological core ground reorientation technology combines the spatial spherical geometry model and borehole bending measurement principle to reorient the geological core on an indoor calibration stage. This technology allows geological core orientation to be separated from the drilling process without the need for in-borehole operation and has the advantages of simple operation, high accuracy, and low cost.

(2) The AE in situ stress tests were carried out with reorientation geological cores to analyze the distribution of in situ stress in deep $(1040 \mathrm{~m})$ borehole in the Xiangxi Gold Mine. The results show that the in situ stress changes from being dominated by horizontal stress to being dominated by vertical stress with depth. The horizontal maximum principal stress and vertical stress gradually increase with depth and reach a high-stress level (greater than $25 \mathrm{MPa}$ ) at a depth of $1000 \mathrm{~m}$. The direction of the maximum principal stress is near north.

(3) In order to comparatively analyze the accuracy of the measured in situ stress, Xiangxi gold mine carried out verification in situ stress measurement in the underground mine with the stress relief method. The distribution of deep in situ stress obtained by the stress relief method agrees well with that by the AE 
method, which proves the reliability of $\mathrm{AE}$ in situ stress testing method based on the geological core ground reorientation technology.

\section{Data Availability}

The data used to support the findings of this study are available from the corresponding author upon request.

\section{Conflicts of Interest}

The authors declare that they have no conflicts of interest.

\section{Acknowledgments}

The work described in this paper was supported by the National Nature Science Foundation of China (Grant nos. 51927808 and 52074352).

\section{References}

[1] X. Ge and M. Hou, "Principle of in-situ 3D rock stress measurement with borehole wall stress relief method and its preliminary applications to determination of in-situ rock stress orientation and magnitude in Jinping hydropower station," Science China Technological Sciences, vol. 55, no. 4, pp. 939-949, 2012.

[2] L. J. Wang, D. S. Sun, W. R. Lin et al., "Anelastic strain recovery method to determine in-situ stress and application example," Chinese Journal of Geophysics-Chinese Edition, vol. 55, no. 5, pp. 1674-1681, 2012.

[3] X. Yang, J. Pang, H. Lou, and L. Fan, "Characteristics of in situ stress field at Qingshui coal mine," International Journal of Mining Science and Technology, vol. 25, no. 3, pp. 497-501, 2015.

[4] M. Cai and E. T. Brown, "Challenges in the mining and utilization of deep mineral resources," Engineering, vol. 3, no. 4, pp. 432-433, 2017.

[5] X. Li, F. Gong, M. Tao et al., "Failure mechanism and coupled static-dynamic loading theory in deep hard rock mining: a review," Journal of Rock Mechanics and Geotechnical Engineering, vol. 9, no. 4, pp. 767-782, 2017.

[6] H. P. Xie, F. Gao, and Y. Ju, "Research and development of rock mechanics in deep ground engineering," Chinese Journal of Rock Mechanics and Engineering, vol. 34, no. 11, pp. 2161-2178, 2015.

[7] X. B. Li, J. Zhou, S. F. Wang, and B. Liu, "Review and practice of deep mining for solid mineral resources," The Chinese Journal of Nonferrous Metals, vol. 27, no. 6, pp. 1236-1262, 2017.

[8] F.-q. Gong, Y. Luo, X.-b. Li, X.-f. Si, and M. Tao, "Experimental simulation investigation on rockburst induced by spalling failure in deep circular tunnels," Tunnelling and Underground Space Technology, vol. 81, pp. 413-427, 2018.

[9] F.-q. Gong, X.-f. Si, X.-b. Li, and S.-y. Wang, "Experimental investigation of strain rockburst in circular caverns under deep three-dimensional high-stress conditions," Rock Mechanics and Rock Engineering, vol. 52, no. 5, pp. 1459-1474, 2019.

[10] P. K. Kaiser and M. Cai, "Design of rock support system under rockburst condition," Journal of Rock Mechanics and Geotechnical Engineering, vol. 4, no. 3, pp. 215-227, 2012.
[11] L. R. E. Sousa, T. Miranda, R. L. E. Sousa, and J. Tinoco, "The use of data mining techniques in rockburst risk assessment," Engineering, vol. 3, no. 4, pp. 552-558, 2017.

[12] D. Goswami, P. Hazarika, and S. Roy, "In situ stress orientation from $3 \mathrm{~km}$ borehole image logs in the Koyna Seismogenic zone, Western India: implications for transitional faulting environment,” Tectonics, vol. 39, no. 1, 17 pages, 2020.

[13] H. J. Guo, J. Ming, and W. S. Zhao, "Analysis of the distribution characteristics and laws of in situ stress in China's coal mines," Arabian Journal of Geosciences, vol. 13, no. 12, 14 pages, 2020.

[14] Y. Li, S. Fu, L. Qiao, Z. Liu, and Y. Zhang, "Development of twin temperature compensation and high-level biaxial pressurization calibration techniques for CSIRO in-situ stress measurement in depth," Rock Mechanics and Rock Engineering, vol. 52, no. 4, pp. 1115-1131, 2019.

[15] W. Yang, B. Lin, C. Zhai, X. Li, X. Sun, and C. Zhang, "A new technology for coal and gas control based on the in situ stress distribution and the roadway layout," International Journal of Mining Science and Technology, vol. 22, no. 2, pp. 145-149, 2012.

[16] D. Sun, W. Lin, J. Cui et al., "Three-dimensional in situ stress determination by anelastic strain recovery and its application at the Wenchuan Earthquake Fault Scientific Drilling Hole-1 (WFSD-1)," Science China Earth Sciences, vol. 57, no. 6, pp. 1212-1220, 2014.

[17] H. Peng, X. M. Ma, J. J. Hang, and Z. Li, "In-situ stress measurements in the WFSD-1 borehole at the Wenchuan earthquake fault," Acta Geologica Sinica-English Edition, vol. 89, no. 3, pp. 1049-1050, 2015.

[18] C. Zhang, M. Wu, Q. Chen, and C. Liao, "Piezomagnetic insitu stress monitoring and its application in the Longmenshan fault zone," Acta Geologica Sinica-English Edition, vol. 88, no. 5, pp. 1592-1602, 2014.

[19] X. Zhao, "Application of the Kaiser effect of acoustic emission to measure vertical stress in an underground mine," InsightNon-destructive Testing and Condition Monitoring, vol. 54, no. 12, pp. 662-666, 2012.

[20] J. Bai, H. Peng, X. Ma, J. Jiang, and Z. Li, "Hollow inclusion strain gauge geostress measuring instrument in deep borehole and its application example," Chinese Journal of Rock Mechanics and Engineering, vol. 32, no. 5, pp. 902-908, 2013.

[21] M. Hou, "Studies on new method and principle of three dimensional crustal stress measurement in deep borehole and related issues," Chinese Journal of Rock Mechanics and Engineering, vol. 23, no. 24, p. 5258, 2004.

[22] R. Christiansson, "The Latest Developments for In-Situ Rock Stress Measuring Techniques,", 2006.

[23] H. P. Kang, J. Lin, and X. Zhang, "Research and application of in-situ stress measurement in deep mines," Chinese Journal of Rock Mechanics and Engineering, vol. 26, no. 5, pp. 929-933, 2007.

[24] J. Chen, X. Li, and H. Cao, "Experimental investigation of coal-like materials for hydraulic fracturing based on fluidsolid interaction," Journal of Natural Gas Science and Engineering, vol. 69, 2019.

[25] D. S. Subrahmanyam, "Evaluation of hydraulic fracturing and overcoring methods to determine and compare the in situ stress parameters in porous rock mass," Geotechnical and Geological Engineering, vol. 37, no. 6, pp. 4777-4787, 2019.

[26] M. F. Cai, "Techniques for in-situ stress measurement at great depth," Journal of University of Science and Technology Beijing, vol. 11, no. 6, pp. 486-488, 2004. 
[27] H. G. Li, R. Zhang, M. Z. Gao, G. Wu, and Y. F. Zhang, "Advances in technology of acoustic emission of rock," Chinese Journal of Underground Space and Engineering, vol. 9, no. 1, pp. 1794-1804, 2013.

[28] F. Q. Zhang, J. S. Song, Z. Y. Shen et al., “A study on fracture orientation and characteristic of remnant paleomagnetization of deep-burial volcanic rocks, north of the Songliao Basin," Chinese Journal of Geophysics-Chinese Edition, vol. 50, no. 4, pp. 1167-1173, 2007.

[29] Y. Lu, M. Chen, Y. Jin, W. Wu, and Y. Li, "A new method for determination of geographic orientation of deep formation geostress," Chinese Journal of Rock Mechanics and Engineering, vol. 30, no. 2, pp. 233-237, 2011.

[30] K. Du, X. F. Li, M. Tao, and S. F. Wang, "Experimental study on acoustic emission (AE) characteristics and crack classification during rock fracture in several basic lab tests," International Journal of Rock Mechanics and Mining Sciences, vol. 133, 2020.

[31] K. Peng, Z. Liu, Q. Zou, Q. Wu, and J. Zhou, "Mechanical property of granite from different buried depths under uniaxial compression and dynamic impact: an energy-based investigation," Powder Technology, vol. 362, pp. 729-744, 2020. 